\title{
Fabrication of BLDC Driving Module for Appliance Applications
}

\author{
Jin-Hong Kim ${ }^{1,2}$, Joon Sung Park ${ }^{1}$, Jun-Hyuk Choi $^{1}$, Chung-Yuen Won ${ }^{2}$ \\ ${ }^{1}$ Korea Electronics Technology Institute ${ }^{2}$ University of Sungkunkwan
}

\begin{abstract}
In order to prevent global warming and save resources, there has been a pressing need in recent years to improve the efficiency of home appliance. Appliance applications such as washers, dryers, air conditioners, and refrigerators, have long been users of conventional induction motor and DC motor for operating pumps, compressors, blowers, fans and agitators as common examples. To meet the increasing demand of energy saving, the induction motor and DC motor in home appliance applications are rapidly being replaced with brushless DC motor. This paper deals primarily with the design aspects of the brushless DC motor drive for appliance applications.
\end{abstract}

Keywords: - brushless DC motor (BLDC), motor drive, trapezoidal commutation, appliance, lead angle

\section{INTRODUCTION}

Because of recent environmental issues, national efficiency regulations are being strengthened and the market demand for high efficiency machine is increasing. In order to improve the efficiency, it is needed to improve the efficiency of the system or to reduce the losses. To meet the demand for high efficient appliances, manufacturers are looking for new ways to meet the challenge without increasing their product costs. Demands for high efficiency and compact volume have motivated to replace the DC motor and the induction motor with the BLDC motor. The BLDC motor has a number of advantages such as high efficiency, high power factor, high power density, low acoustic noise and low maintenance cost. Moreover, the rapid growth of solid-state power semiconductor technology made it increasingly practical to introduce BLDC motor drives. However, the BLDC motor needs more complex motor drive comparing with the DC motor and induction motor drive. One of the complicated points is current delay problem in high speed which is induced by impedance of inductance at high frequency. For this reason, it is difficult to operate in a wide range of the speed, particularly such as high speed operation. In order to solve this problem, lead angle injection has been utilized. But, there is no common rule in lead angle decision. This paper describes a lead angle adjustment method for BLDC motor. Tozune [2], Park [3], and Safi [4] showed the validity of the lead angle injection for high speed BLDC drive. They have verified that output performance has improved in motor current and output torque with lead angle injection and proposed a way of lead angle adjustment rules also. However, the rules are based on the experimental results not by theoretical perspectives. This paper deals primarily with the design aspects of the BLDC drive for appliance applications. Experimental results from laboratory prototype are presented to validate the feasibility.

\section{CONVENTIONAL BLDC DRIVE CONTROL}

Fig. 1 shows the typical inverter configuration and BLDC motor. Generally, the BLDC motor is wound in a three-phase wye configuration. This configuration connects one end of each phase together to make a center point of a "Y" or the motor neutral point. This is then driven by a three-phase inverter with what is called trapezoidal commutation. At any step, only two of the three phases are conducting current where current flows into one phase and then out another. For instance, when phase A and B conduct current, phase $\mathrm{C}$ is floating.

Consider the operation of the BLDC motor with six-switch inverter topology. Fig. 2 shows hall-effect sensor output, back-EMF and phase current waveforms, where the rotor is rotating in a counter clockwise direction at a speed of $\omega_{\mathrm{m}}$ which is driven by the inverter using trapezoidal commutation. This emf waveform has a flat portion, which occurs for at least 120 electrical degree during each half-cycle. The amplitude $\mathrm{E}$ is proportional to the rotor speed. 


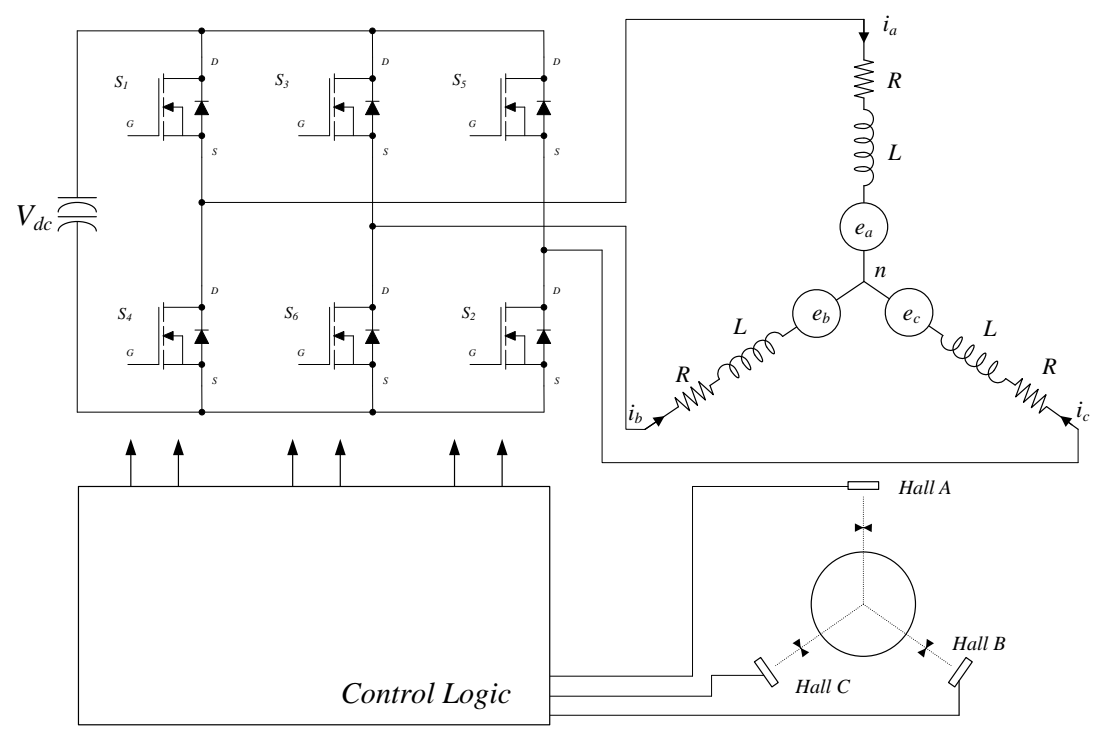

Fig. 1. Inverter configuration.
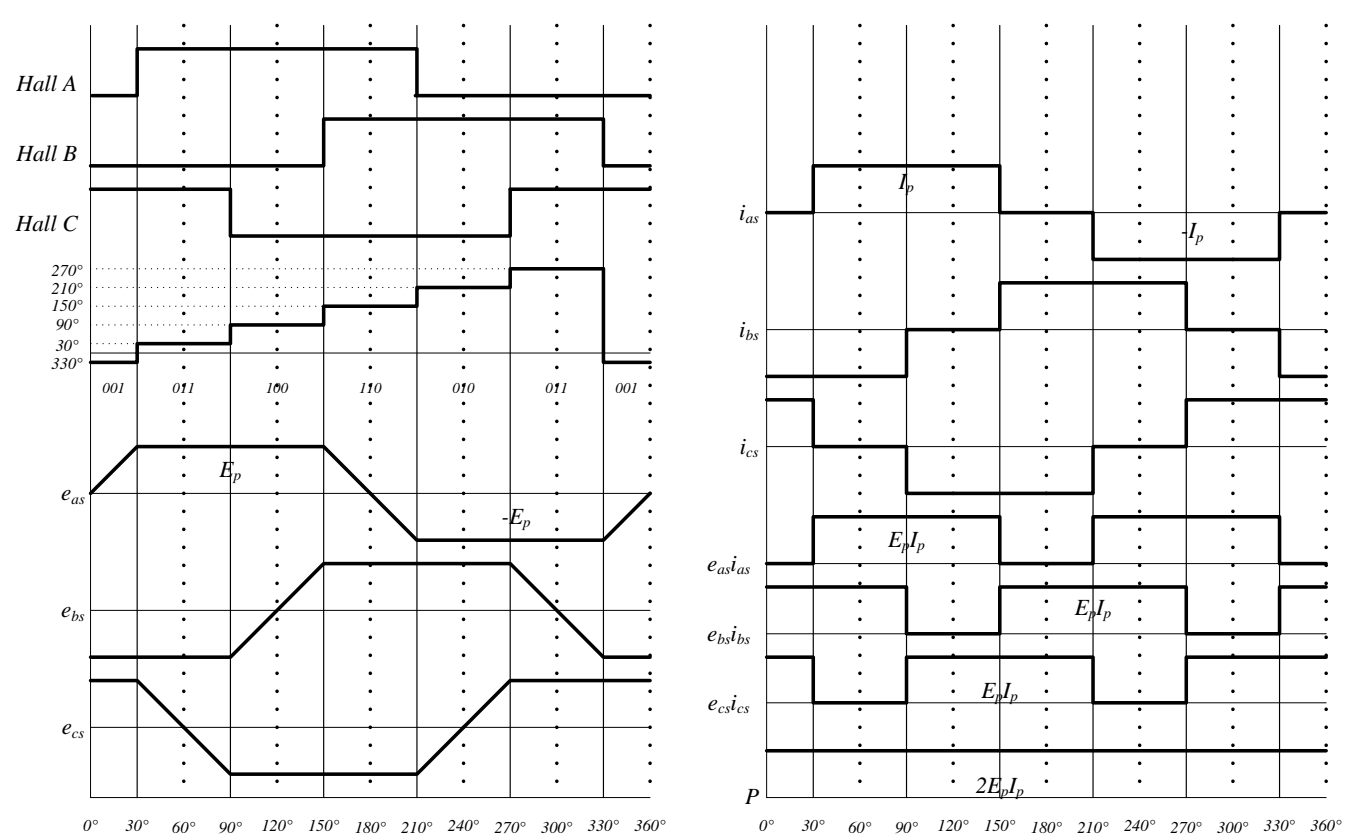

Fig. 2. BLDC motor waveforms.

\section{BLDC LEAD ANGLE ADJUSTMENT SCHEME}

The model of BLDC motor in phase variables is represented as follows. The term of stator winding resistance is much smaller than other terms. Therefore, Ignoring stator resistance, BLDC motor can represented as

$$
\left[\begin{array}{c}
V_{a} \\
V_{b} \\
V_{c}
\end{array}\right]=L \frac{d}{d t}\left[\begin{array}{l}
i_{a} \\
i_{b} \\
i_{c}
\end{array}\right]+\left[\begin{array}{c}
e_{a} \\
e_{b} \\
e_{c}
\end{array}\right],
$$

where $V_{a n}, V_{b n}, V_{c n}$ the applied inverter phase voltage, $i_{a}, i_{b}, i_{c}$ motor current, $L$ sum of the self and mutual inductance of each phase. It has been assumed that each phase back-EMF waveform has a half-wave symmetrical form and also has same magnitude for three phase winding with $2 \pi / 3$ [rad] phase shift each other. Also, current is achieved to demand level by using current controlled unipolar PWM strategy. At low speed, the current waveform is close to the rectangular waveform, with a phase voltage applied during each phaseconduction interval to force the necessary change in current level. During each interval, the applied voltage exceeds the back-EMF by a amount equal to the voltage drop across the winding resistance. 


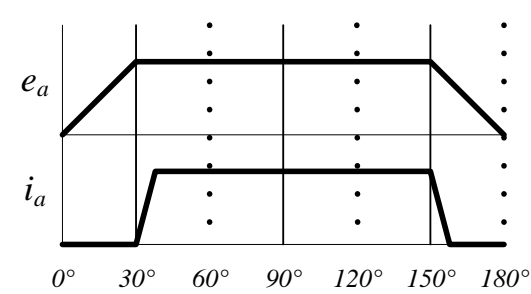

(a)

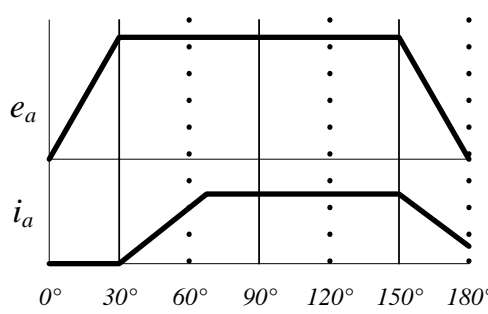

(b)

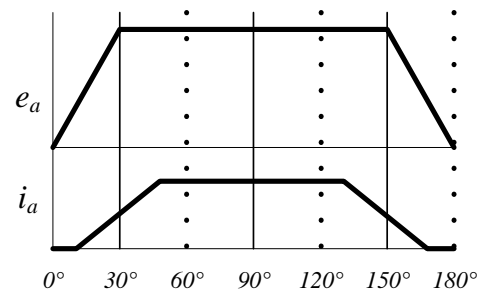

(c)

Fig. 3. Back-emf and phase current waveforms. (a) at low speed without lead angle injection. (b) at high speed without lead angle injection. (c) at high speed with lead angle injection.

At high speed, the inductive reactance of the windings makes a significant time delay and as a result, the time taken for the current to increase to its demand value occupies a large portion of the phase conduction interval and the demand current level is not attained only at the start of the interval. The output torque of the drive decreases also since the current magnitude is low and it is out of phase with the back-EMF. This situation can be compensated to some extent by injecting each phase voltage earlier which is called lead angle adjustment. With lead angle adjustment, phase current in the motor winding is allowed to be built up before the back-EMF reaches any significant level. Also, the current waveform is closed to rectangular waveform and operate BLDC motor effectively over a wide range, the switches must be turned on in advance of the rising back-EMF region so as to allow time for the current to be built up. Fig. 3 shows the back-EMF and phase current waveform at the low speed and high speed. At low speed Fig. 3 (a), the current built up effective to demand level quickly since the back-EMF and impedance of motor inductor are low. However, at high speed, the back-EMF and impedance of inductor are quite high. As shown in Fig. 2 (b), phase current time delay from zero to demand level has quite portion of the overall interval. This decrease output torque and increase torque ripple. Hence, by injecting phase voltage in advance Fig. 3 (c), the current level reaches its demand level earlier and current delay can be compensated easily.

When phase change from a-phase to b-phase with constant c-phase current $\left(i_{a} \rightarrow 0, i_{b} \rightarrow I_{d}\right.$, and $\left.i_{c}=-I_{d}\right)$, the phase current dynamics are given by

$$
\begin{aligned}
& L \frac{d i_{a}}{d t}=-\frac{V_{d c}}{2}-\frac{e_{a}}{2}+\frac{e_{b}}{2}, \\
& L \frac{d i_{b}}{d t}=\frac{V_{d c}}{2}-\frac{e_{a}}{2}+\frac{e_{b}}{2} .
\end{aligned}
$$

In equation (2), phase currents are derived from the integration of DC-link voltage, the back-EMF $e_{a}$ and $e_{b}$. Hence, during the current change interval, if we let the integration of back-EMF $e_{a}$ and $e_{b}$ be the same magnitudes with opposite sign, (2) is represented as

$$
\begin{aligned}
& i_{a}=-\frac{1}{L} \int_{t 1}^{t 2} \frac{V_{d c}}{2} d t, \\
& i_{b}=\frac{1}{L} \int_{t 1}^{t 2} \frac{V_{d c}}{2} d t,
\end{aligned}
$$

where $\mathrm{t} 1$ and $\mathrm{t} 2$ are phase change beginning and end time. Without lead angle adjustment, $\mathrm{t} 0$ is the phase change time. To make the integration of back-EMF $e_{a}$ and $e_{b}$ be the same magnitudes, $t 1$ and $t 2$ are selected as $t 0-t 1=t 2-$ t0 since the back-EMF waveform has half symmetrical form and also has same magnitude for the three phase windings with phase shift each other. Fig. 3 shows the lead angle adjustment and $t 1$, $t 2$. Hence the lead angle adjustment time $t_{1}$ is given by

$$
t_{l}=\frac{2 L I_{d}}{V_{d c}} .
$$

With injecting proposed lead angle adjustment time $t_{1}$, the phase back-EMF and phase current have the identical phase angle and the motor efficiency and output power are increased. 

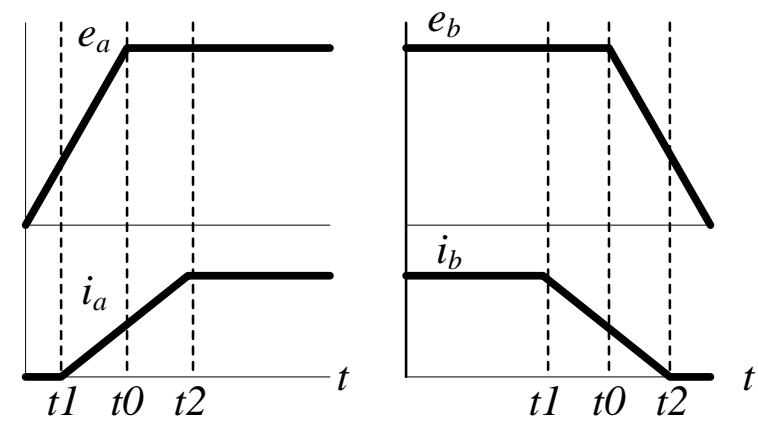

Fig. 4. Bak-EMF and phase current waveform with proposed lead andgle adjustment rule.

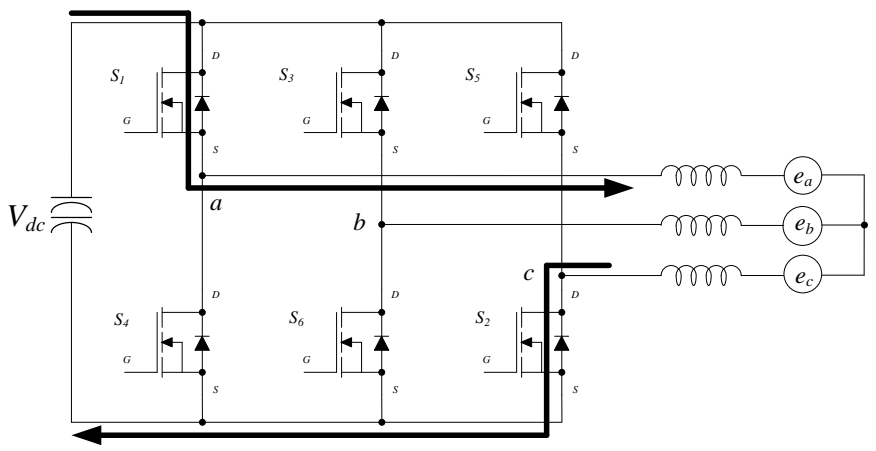

(a) $\mathrm{t}<\mathrm{t} 1$.

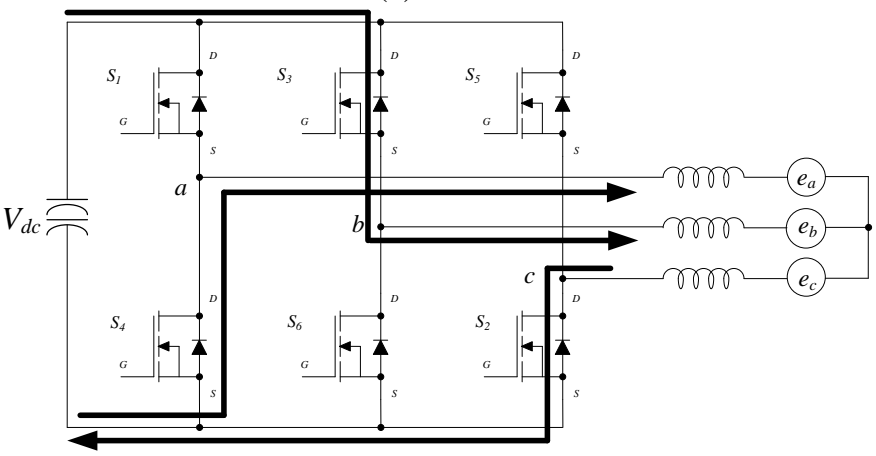

(b) $\mathrm{t} 1<\mathrm{t}<\mathrm{t} 2$.

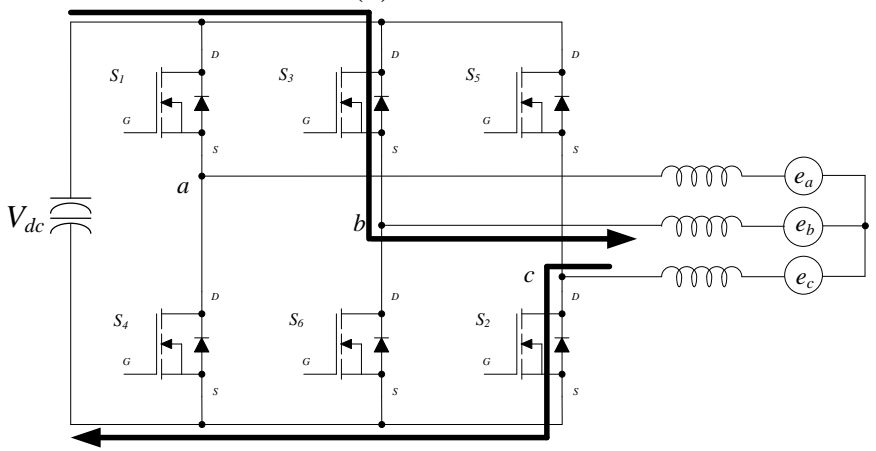

(c) $t>t 2$.

Fig. 5. Current conduction for (a) $\mathrm{t}<\mathrm{t} 1$, (b) $\mathrm{t} 1<\mathrm{t}<\mathrm{t} 2$, (c) $\mathrm{t}>\mathrm{t} 2$. 


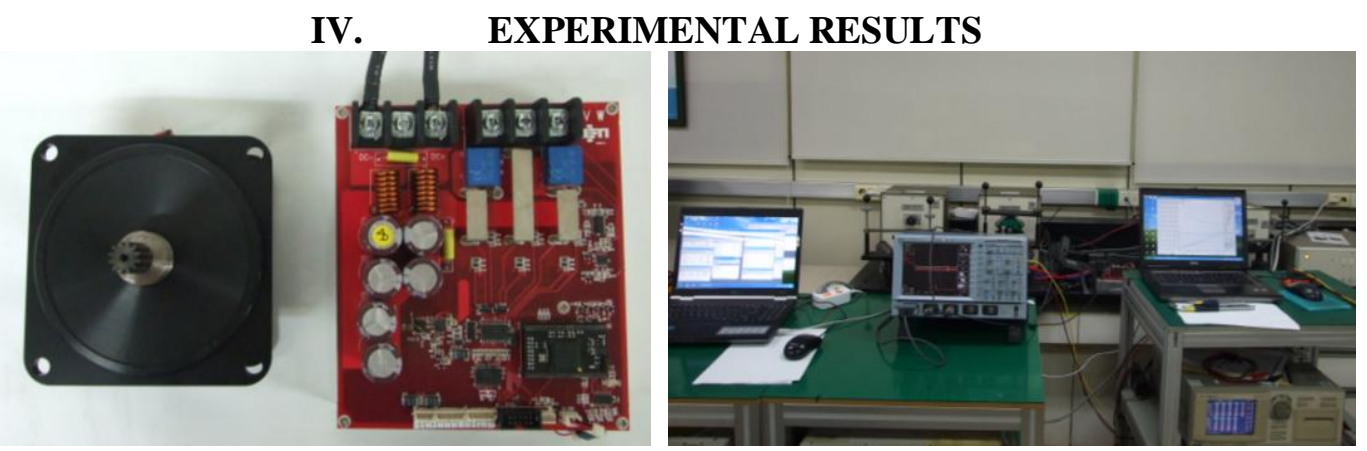

Fig. 6. Photos of the BLDC motor, inverter drive and experimental setup.

In order to verify the proposed lead angle adjustment rule, the BLDC motor and drive were tested extensively with dynamometer lead and evaluated its performance. Fig. 6 shows the BLDC motor, inverter and experimental setup. The specification of the BLDC motor is presented in table I.

TABLE I. Specification of BLDC Motor

\begin{tabular}{|l|c|c|}
\hline \multicolumn{1}{|c|}{ Item } & Unit & Specification \\
\hline Output power & $\mathrm{W}$ & 300 \\
\hline Number of poles & - & 4 \\
\hline Resistance & $\Omega$ & 0.15 \\
\hline Inductance & $\mu \mathrm{H}$ & 450 \\
\hline
\end{tabular}

Fig. 9-12 show the experimental waveforms in case of full duty from no load to rated torque which is 0.6 [Nm]. And Fig. 8 shows the experimental waveforms at $0.8[\mathrm{Nm}]$ which is proposed method. Due to the inductive reactance of the windings of BLDC motor is delayed significant time, as shown in Fig. 9-12. After injecting each phase voltage early by the proposed lead angle adjustment method, current level is reduced. For this reason, torque ripple is reduced and output power and speed are increased in comparison with conventional method. Fig. 7 shows NTI curve. In comparison with conventional method, the speed and the efficiency of proposed method increase.

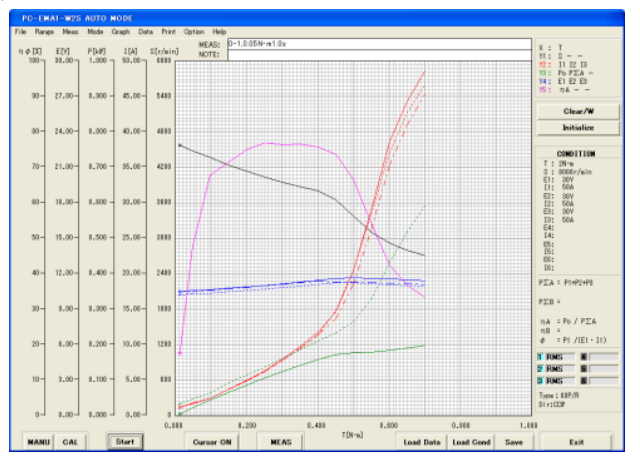

(a) with conventional method.

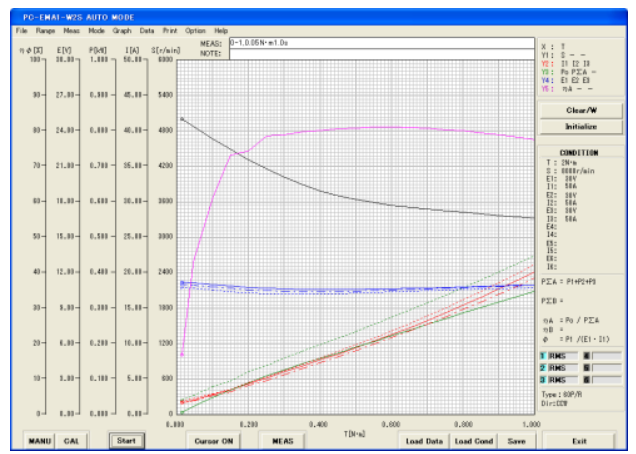

(b) with proposed method.

Fig. 7. NTI curve.

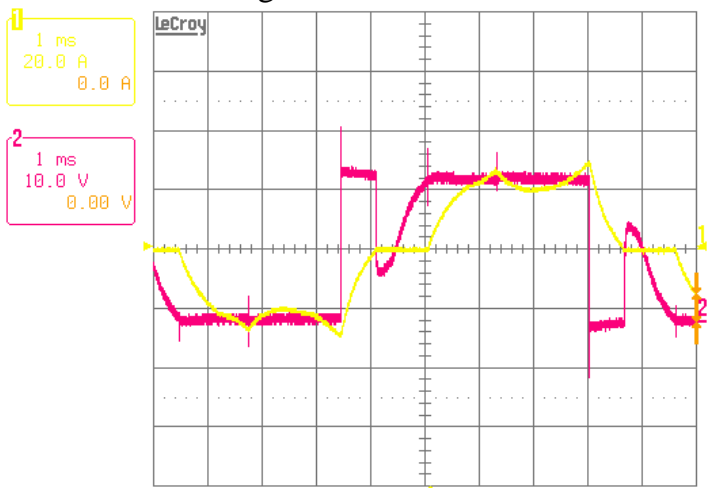

Fig. 8. Experimental waveforms with proposed method. (duty 100\%, max speed@0.8Nm). 


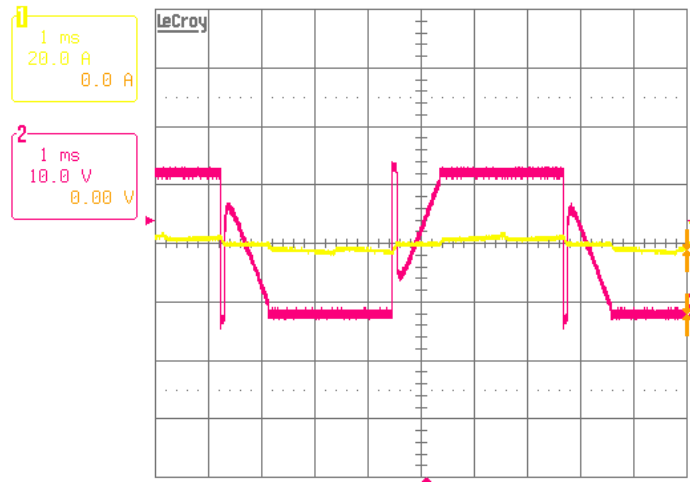

(a) With conventional method.

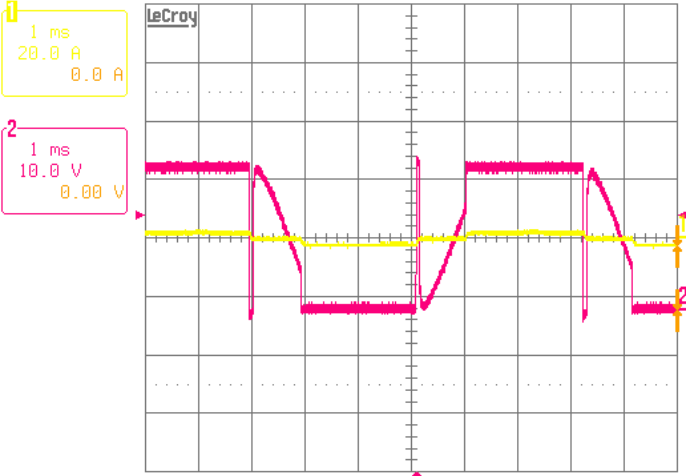

(b) With proposed method.

Fig. 9. Experimental waveforms I. (duty 100\%, max speed@0Nm).

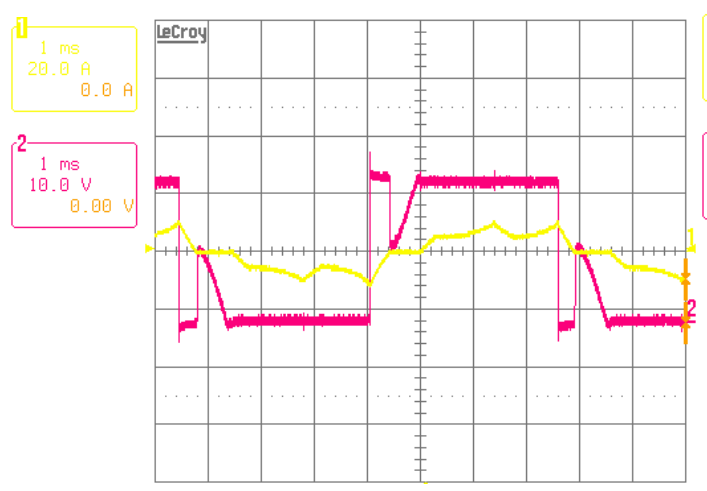

(a) With conventional method.

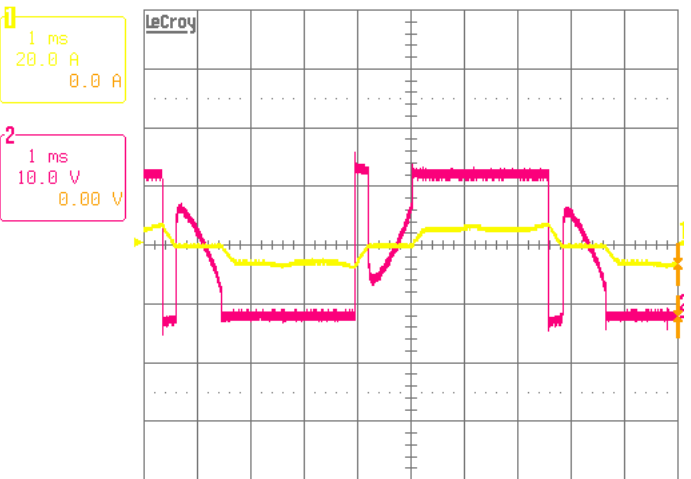

(b) With proposed method.

Fig. 10. Experimental waveforms II. (duty 100\%, max speed@0.2Nm).

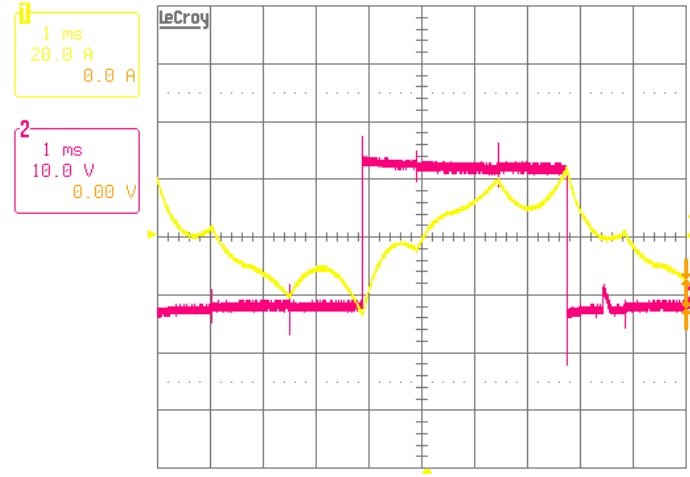

(a) With conventional method.

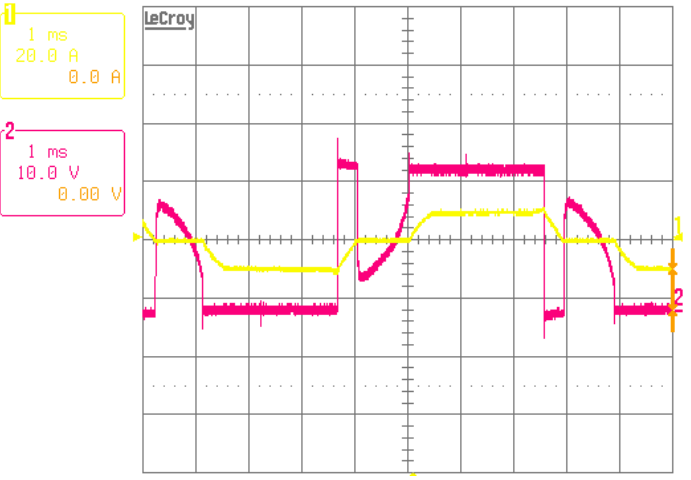

(b) With proposed method.

Fig. 11. Experimental waveforms III. (duty 100\%, max speed@0.4Nm).

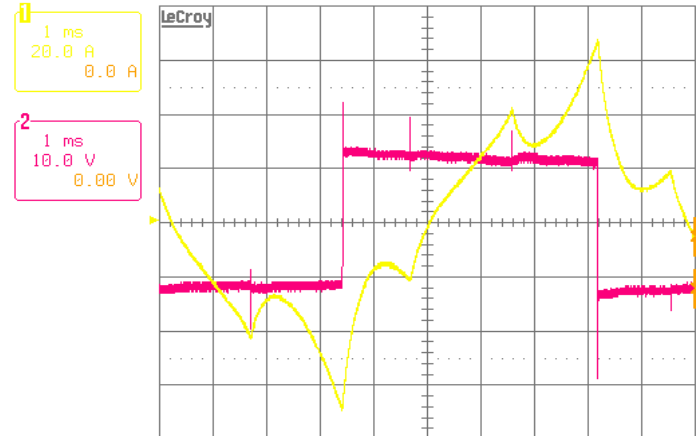

(a) With conventional method.

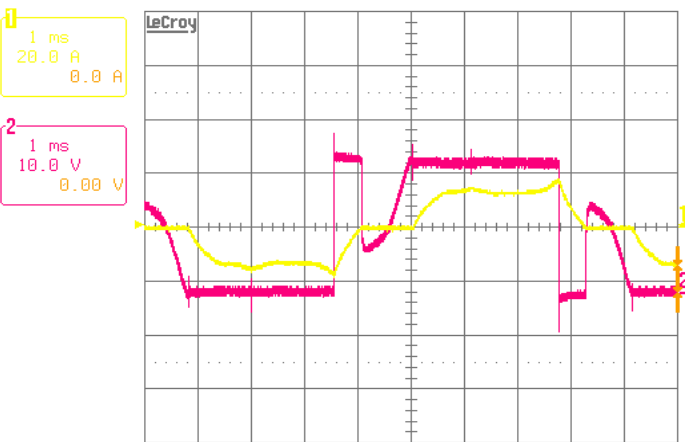

(b) With proposed method.

Fig. 12. Experimental waveforms IV. (duty 100\%, max speed@0.6Nm). 


\section{CONCLUSION}

This paper presents a lead angle adjustment method of BLDC motor to operate wide range of speed for appliance applications. Through the experimental results, the BLDC motor drive is implemented effectively by using proposed lead angle adjustment method. Lead angle is simply calculated by inductance, current and DClink voltage. In this way, operating speed and efficiency are increased. The current, power and speed performances using the proposed method are tested in comparison with conventional method which do not inject a lead angle. Through the simply calculated lead angle adjustment, operating speed of the BLDC motor is improved and also current ripple is improved.

\section{ACKNOWLEDGEMENTS}

This work was supported by the Energy Efficiency \& Resources of the Korea Institute of Energy Technology Evaluation and Planning (KETEP) grant funded by the Korea government Ministry of Knowledge Economy. (No. 20132020101850)

\section{REFERENCES}

[1] Zeraoulia M., Benbouzid M.E.H., and Diallo D., Electric Motor Drive Selection Issues for HEV Propulsion Systems : A Comparative Study, IEEE Trans. Vehicular Technology, Vol. 55, Iss. 6, pp. 17561764, Nov. 2006.

[2] A. Tozune, and T. Takeuchi, Improvement of torque-speed characteristics of brushless motor by automatic lead angle adjustment, IPEMC 2004, pp 583-587, 2004.

[3] S. I. Park, T. S. Kim, S. C. Ahn, and D. S. Hyun, An improved current control method for torque improvement of high-speed BLDC motor, APEC '03, pp 294-299, 2003.

[4] S. K. Safi, P. P. Acarnley, and A. G. Jack, Analysis and simulation of the high-speed torque performance of brushless DC motor drives, IEE Proc.-Electr. Power Appl., Vol. 142, No. 3, May 1995.

[5] Richard Valentine, Motor Control Electronics Handbook, (McGraw-Hill Handbooks, 1998).

[6] T.J.E. Miller, and Hendershot, Design of Brushless Permanent-Magnet Motors, (Magna Physics publishing and Clarendon Press, Oxford, 1994).

[7] R. Krishnan, Electric Motor Drives, (Prentice Hall, Inc. 2001).

[8] Grodon R. Slemon, "High-Efficiency Drives Using Permanent-Magnet Motors", Proc. Of IEEE IECON, pp.725-730, 1993.

[9] Kwanghee Nam, AC Motor Control and Electric Vehicle Applications, (CRC Press, 2010). 